\title{
Испытания на воздействие прямого удара молнии на авиационное оборудование
}

\author{
А. Петровичев ${ }^{1}$
}

УДК 629.7.018 | ВАК 05.11.01

\begin{abstract}
Последствия попадания молнии в летательный аппарат (самолет или вертолет) могут быть фатальными - от отказа отдельных узлов, выполняющих критически важные функции, до взрывов, пожаров и гибели людей, находящихся на борту. Разумеется, современная авиационная техника оборудуется соответствующими системами защиты, что в то же время полностью не исключает риска попадания молнии в борт. Именно по этой причине проводятся испытания на стойкость к прямому удару молнии. В статье на примере раздела 23.0 квалификационных требований КТ-160G/14G для авиации рассматривается порядок проведения испытаний, требования к оборудованию и методам оценки результатов, а также возможные проблемы и пути их решения при реализации испытаний.
\end{abstract}

\section{АЛГОРИТМ ПРОВЕДЕНИЯ ИСПЫТАНИЙ}

Молния - это электрический разряд, возникающий в атмосфере. Для ее образования требуется, чтобы в относительно малом объеме возникла достаточная для дальнейшего пробоя напряженность электрического поля (порядка 1 МВ / м). Пробой возникает между обозначенным объемом и областью или объектом со значительно более низким потенциалом. Такими областями могут быть пространство в самом грозовом облаке, поверхность земли (или объект на ней), а также объекты, находящиеся в воздухе, в частности летательные аппараты.

Испытания авиационной техники на стойкость к прямому удару молнии проводят на соответствие КТ-160G/14G, в частности требованиям раздела 23.0 Данный раздел распространяется на оборудование, установленное снаружи основной обшивки летательного аппарата: антенны, устройства внешнего светотехнического оборудования, датчики воздушных сигналов, наружные датчики, противообледенительные системы, установленные снаружи планера, магнитные индикаторы уровня жидкости, крышки заправочных горловин топлива, сливные клапаны и т. д. На оборудование, являющееся неотъемлемой частью планера,

АО «ТЕСТПРИБОР», заместитель начальника ИЛ ЭМС требования этого раздела не распространяются - его испытания на молниестойкость проводят по отдельным методиками и / или в составе планера целиком. Точно так же в данном разделе не приводятся требования по стойкости к косвенным воздействиям, вызванным молнией, - они представлены в разделе 22.0 и в статье не рассматриваются.

Испытание на стойкость к прямому воздействию молнии разделяют на два вида проверок: контакт оборудования с высоковольтным разрядом и воздействие сильным током. Первая проверка требуется для определения возможных мест контакта молнии с испытуемым объектом. Вторая - для оценки возможных повреждений, которые объект может получить при проходе канала молнии по нему или в непосредственной близости с ним. Существует строгая последовательность проведения испытаний: сначала объект подвергается воздействию высоковольтного разряда и только затем - сильным током в местах, где возник контакт объекта с молнией.

Рассмотрим алгоритм проведения испытаний (рис. 1). Сначала нужно определить, требуется ли проверка на воздействие высоковольтным разрядом. Если да - проводится испытание, по результатам которого определяют, соответствует ли изделие предъявляемым к нему требованиям. В случае успешного 
проведения испытаний или когда испытание на воздействие высоковольтного разряда не требуется (например, если оборудование не имеет диэлектрических покрытий), переходят к воздействию сильным током, если требуется данная проверка. По результатам испытаний определяют соответствие изделия предъявляемым требованиям. Проверку сильным током могут не проводить в случае, если не удалось в ходе предыдущей проверки выявить места контакта с молнией.

Оборудование, предоставляемое для испытаний, проходит проверку в выключенном состоянии, но с одним исключением. Если включенное электропитание изменяет восприимчивость к прямому воздействию молнии, то на оборудование должно быть подано питание или должны применяться средства, имитирующие включение питания.

Оценка результата испытаний проводится в соответствии с технической документацией на испытуемое изделие. Должно быть четко прописано, согласно каким критериям считать испытуемое изделие выдержавшим испытание. Например, в результате воздействия сильным током может произойти оплавление или разрушение обтекателя изделия, но само оно остается способным выполнять свои основные функции. С одной стороны, изделие не выдержало разрушающего воздействия, с другой - прошло проверку функционирования.

\section{КАК РЕАЛИЗОВАТЬ ИСПЫТАНИЯ}

Что нужно для того, чтобы реализовать подобные испытания?

В первую очередь необходимо обеспечить подходящую испытательную площадку. Ее габариты должны быть достаточными для реализации высоковольтных разрядов, требования к которым указаны в разделе 23.0. Размеры площадки должны исключить риск разряда на объекты, не относящиеся киспытаниям, и обеспечить безопасность персонала испытательной лаборатории.

Необходимыми компонентами являются генераторы испытательных импульсов. Как было отмечено,

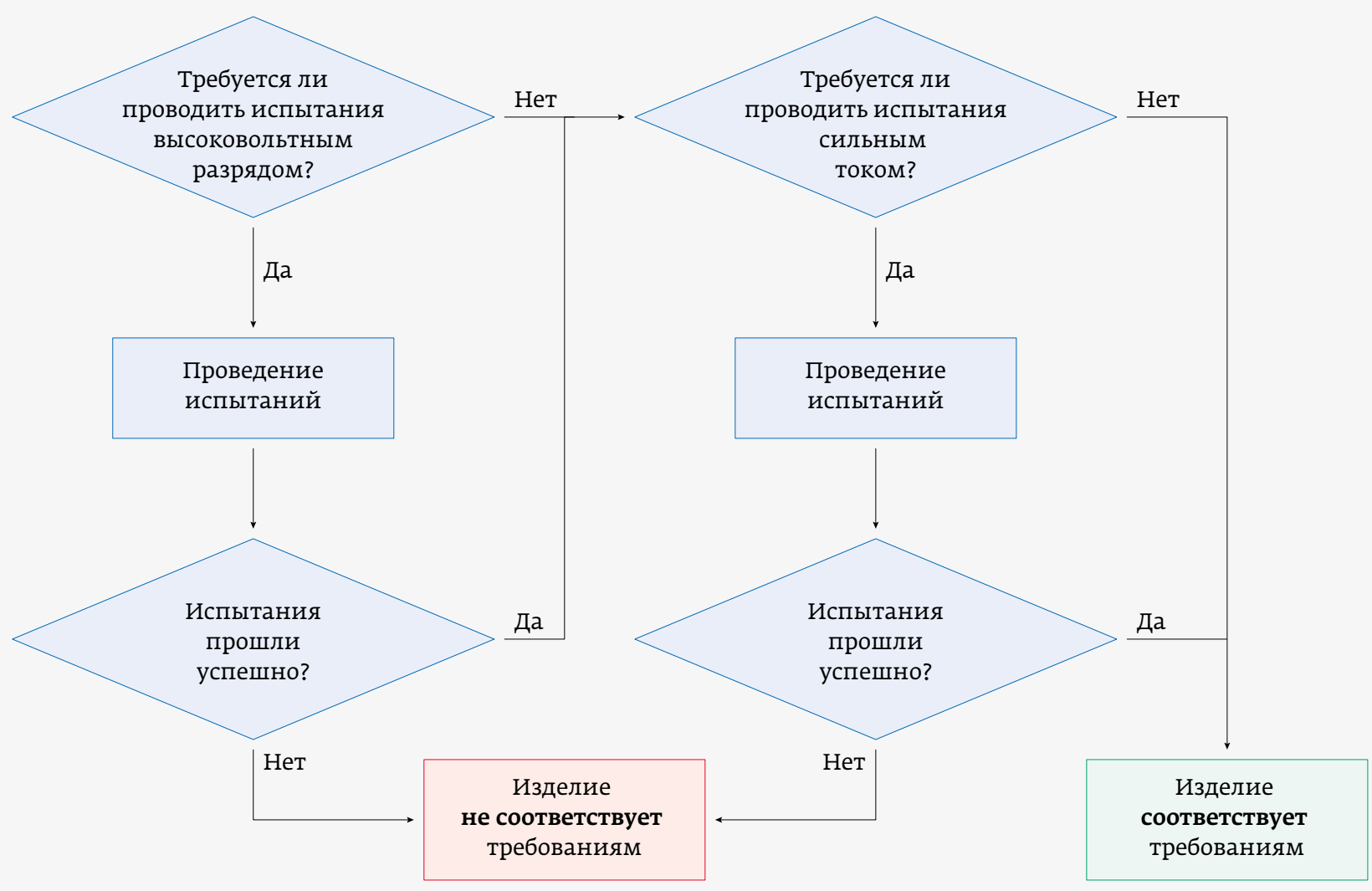

Рис. 1. Алгоритм проведения испытаний на соответствие требованиям раздела 23.0 КТ-160С/14С 
испытания разделены на два этапа. Иными словами, испытуемое оборудование поочередно подвергается воздействию двух видов импульсов: импульса напряжения и импульса тока, для каждого из которых нужен свой генератор.

Обратимся к требованиям раздела 23.0.

Испытание на воздействие высоковольтного разряда предполагает проверку двумя формами импульсов в зависимости от категории испытуемого оборудования. Пиковое значение импульсов может достигать от нескольких сотен до нескольких тысяч киловольт в зависимости от категории; скорость нарастания напряжения при этом должна составлять $1000 \mathrm{kB} / \mathrm{MKC}$.

Испытание на воздействие сильным током предполагает проверку семью видами компонентов тока, наблюдаемых в молнии. Пиковое значение тока может достигать 200 кА.

Резюме: для того, чтобы в лабораторных условиях реализовать полноценные испытания на соответствие требованиям раздела 23.0, требуется подходящая испытательная площадка, испытательные генераторы и обученный персонал.

\section{ПРОБЛЕМЫ, ВОЗНИКАЮЩИЕ ПРИ РЕАЛИЗАЦИИ ИСПЫТАНИЙ, И ПУТИ ИХ РЕШЕНИЯ}

Из требований по реализации испытаний вытекают проблемы, связанные с их выполнением.

В первую очередь, следует уделить внимание выбору испытательной площадки. В разделе 23.0 указаны расстояния, на которых электрод испытательной установки должен находиться относительно испытуемого оборудования. Максимальное расстояние составляет 1,5 м, то есть на расстоянии не менее полутора метров вокруг электрода не должно находиться каких-либо посторонних предметов, на которые может произойти пробой. Это касается как лабораторного оборудования, не относящегося к испытаниям, таки персонала.

Испытательное оборудование, фактически, состоит из набора генераторов и электродов. При этом для каждой формы импульса используется свой генератор, позволяющий регулировать только уровень воздействия - остальные параметры остаются фиксированными. Обеспечение лаборатории таким оборудованием требует значительных затрат. Но даже если позволяют финансовые возможности для оснащения лаборатории, следует учитывать обязательное требование - испытательное оборудование необходимо разместить так, чтобы обеспечить безопасную работу с ним. В идеальном случае в лаборатории имеется достаточно места, чтобы обеспечить подходящую испытательную площадку и размещение оборудования, а для его закупки выделено достаточно финансовых средств. Нет смысла останавливаться на этом случае: после закупки оборудования и обучения персонала можно проводить испытания.

Теперь предположим, что при наличии подходящей площадки лаборатория сильно ограничена с точки зрения финансовых возможностей. В таком случае выходом из ситуации может быть закупка генератора одной формы импульса, с которой, исходя из запросов на проведение испытания, чаще всего сталкиваются заказчики в требованиях на испытуемое оборудование. При этом надо понимать, что такой путь сильно ограничит возможности лаборатории по всему спектру проверок по разделу 23.0 КТ-160G/14G.

Аналогичная ситуация возникает, когда лаборатория не располагает достаточным пространством для размещения испытательной площадки и оборудования. В этом случае решение сводится к проведению испытаний с минимальным расстоянием между испытуемым оборудованием и электродом (0,5 м), что означает невозможность полностью обеспечить требования раздела 23.0.

Наконец, при жестких ограничениях остается вариант самостоятельно разработать испытательные генераторы и методики проведения испытаний, по которым будет осуществляться подтверждение соответствия требованиям раздела 23.0. Но в данном случае возникает проблема, связанная, с одной стороны, с временными и финансовыми затратами на разработку и, с другой стороны, с ограничениями при выполнении всех требований раздела 23.0, также как в первых двух случаях.

\section{ЗАКЛЮЧЕНИЕ}

В настоящий момент в испытательной лаборатории ЭМС АО «ТЕСТПРИБОР» изучены возможные пути реализации испытаний на соответствие требованиям раздела 23.0 КТ-160G / 14G. Было принято решение создать соответствующую установку и площадку на испытательной базе лаборатории.

В качестве испытательного оборудования выбраны генераторы производства EMC Partner, предназначенные для проведения полного объема испытаний, предусмотренного разделом 23.0 KT-160G/14G. Дальнейшим шагом станет обучение персонала лаборатории работе с испытательным стендом. Сразу после аттестации установки лаборатория начнет проведение испытаний на соответствие требованиям на стойкость к прямому удару молнии. 
